\title{
EFFECT OF PROVENANCE AND CLIMATE ON XYLEM ANATOMY OF HALOXYLON AMMODENDRON (C. A. MEY) BUNGE IN THE GURBANTUNGGUT DESERT, CHINA
}

\author{
ZHOU, C. B. ${ }^{1,2}-$ GoNG, W. ${ }^{1 *}$ \\ ${ }^{1}$ Sichuan Provincial Key Laboratory of Ecological Forestry Engineering, College of Forestry, \\ Sichuan Agricultural University, No. 211. Huimin Rd., Wenjiang Dist., Chengdu, \\ Sichuan 611130, China \\ ${ }^{2}$ College of Agriculture, Shihezi University, Shihezi, Xinjiang 832000, China \\ *Corresponding author \\ e-mail: gongwei@sicau.edu.cn \\ (Received 19 ${ }^{\text {th }}$ Jan 2017; accepted 23 $3^{\text {rd }}$ Mar 2017)
}

\begin{abstract}
Although Haloxylon ammodendron is widely distributed in desert regions of both Asia and Africa, the anatomical structure of its xylem is rarely reported. In this study, the differences in xylem anatomical characteristics among five provenances in the southern Gurbantunggut Desert were compared and the effects of climatic factors on anatomical features were analyzed. The results showed that the xylem responded to low precipitation by increasing ray density and ray height to improve the storage of water and starch to combat drought stress. In an arid provenance (Jinghe), H. ammodendron had wide vessels to improve conductivity. Moreover, they increased the vessel wall thickness to decrease its sensitivity to embolism. Both average temperature in January and maximum wind velocity from April to June were significantly related to the wall thickness of the fiber $(P<0.05)$, indicating that a thicker fiber cell wall could provide higher mechanical resistance to steady stems and improve vessel conduction in low temperature and strong wind conditions. These results indicate that there is high plasticity in the xylem anatomical structures of $H$. ammodendron in response to different desert conditions and also explain the adaptation of the plant to a wide range of Asian and African deserts.
\end{abstract}

Keywords: Saxoul; ray; vessel; fiber; precipitation; temperature; wind velocity; adaptation

\section{Introduction}

Haloxylon ammodendron (C.A. Mey) Bunge belongs to the family Amaranthaceae, which is widely distributed in desert ecosystems across Asia and Africa (Pyankov et al., 1999; Tobe et al., 2000). In China, H. ammodendron is the dominant species of vegetation in the Gurbantunggut Desert (Huang et al., 2009). The plant is highly adaptable to drought, salinity, nutrient deficiency and intensive light (Fahn and Cutler, 1992; Huang et al., 2003), so in the Gobi region in southern Mongolia and the arid region of northwest China, H. ammodendron has become the main tree species for afforestation (Bedunah and Schmidt, 2000; Sheng et al., 2005; von Wehrden et al., 2009).

Trees with a wide geographical distribution must adapt to changes in ecological conditions through morphological and physiological variations. The growth characteristics of $H$. ammodendron vary across different regions of the Gurbantunggut Desert. The variations in appearance (e.g. tree height, basal diameter, crown area), seed quality (Lv et al., 2012, 2015) and seedling regeneration (Zhou and Song, 2015) may be 
caused by differences in climate and microhabitat. The xylem of plants provides mechanical support and the transportation and storage of water and nutrients (Esteban et al., 2010). Its microstructure reflects the adaptation of the plant to the natural environment (Carlquist, 2001). Many studies have confirmed that significant variations in the anatomical characteristics of xylems are caused by differences in ecological conditions among different provenances (Esteban et al., 2012; Zas et al., 2015). For a long period, $H$. ammodendron has lived in a desert environment with low precipitation so the xylem is already highly adapted to drought stress (Yang and Furukawa, 2003; Heklau et al., 2012; Li et al., 2015; Song and Zhou, 2015). However, existing studies have not considered the effects of climatic factors in different provenances on xylem anatomical variables.

Anatomical characteristics of the xylem change with environmental conditions, but the variation in xylem tissue among different species is inconsistent. For example, it is expected that wood density is higher and mechanical strength and cavitation resistance is stronger under drought stress (Christensen-Dalsgaard and Ennos, 2012; Plavcová and Hacke, 2012). Studies have also pointed out that with increasing drought stress, the cell wall area of fiber reduces, as a consequence of a decrease in wood density (Aref et al., 2013). Furthermore, contrasting results have been found in the correlations between drought stress and the diameter of vessels (Plavcová and Hacke, 2012; Aref et al., 2013; Menezes-Silva et al., 2015; Hajek et al., 2016) and rays (Margaris and Papadogianni, 1977; Martin et al., 2010). It is currently unclear how the anatomical structure of the xylem of $H$. ammodendron will respond to changes in desert environment.

In this study, five sample plots were created on the Jinghe, Wusu, Shihezi, Caijiahu and Qitai, from West to East, of the southern Gurbantunggut Desert (Fig. 1). Among these sample plots, a significant difference was found in the growth of $H$. ammodendron, and the maximum was double the minimum in average annual precipitation (Table 1). The objectives of this paper were to: (1) compare the differences in xylem anatomical features among provenances; (2) analyze the effects of climatic factors on anatomical variables. We expected to clarify the adaptation of $H$. ammodendron xylem anatomy to ecological conditions, especially drought stress, in different areas.

\section{Materials and Methods}

\section{Experimental set up and climatic conditions}

Sample plots were located at Jinghe, Wusu, Shihezi, Caijiahu and Qitai in the southern Gurbantunggut Desert, China (Fig. 1); the plots have a temperate continental desert climate. Meteorological factors such as temperature, precipitation, wind velocity and sunshine are shown in Table 1. Five unbroken and representative sample trees in each plot were selected, totaling 25 trees. Branches (3-5) with a diameter of about 1 $\mathrm{cm}$ and length of about $15 \mathrm{~cm}$ were sawn from each sample tree in order to measure the anatomical features of the xylem. 


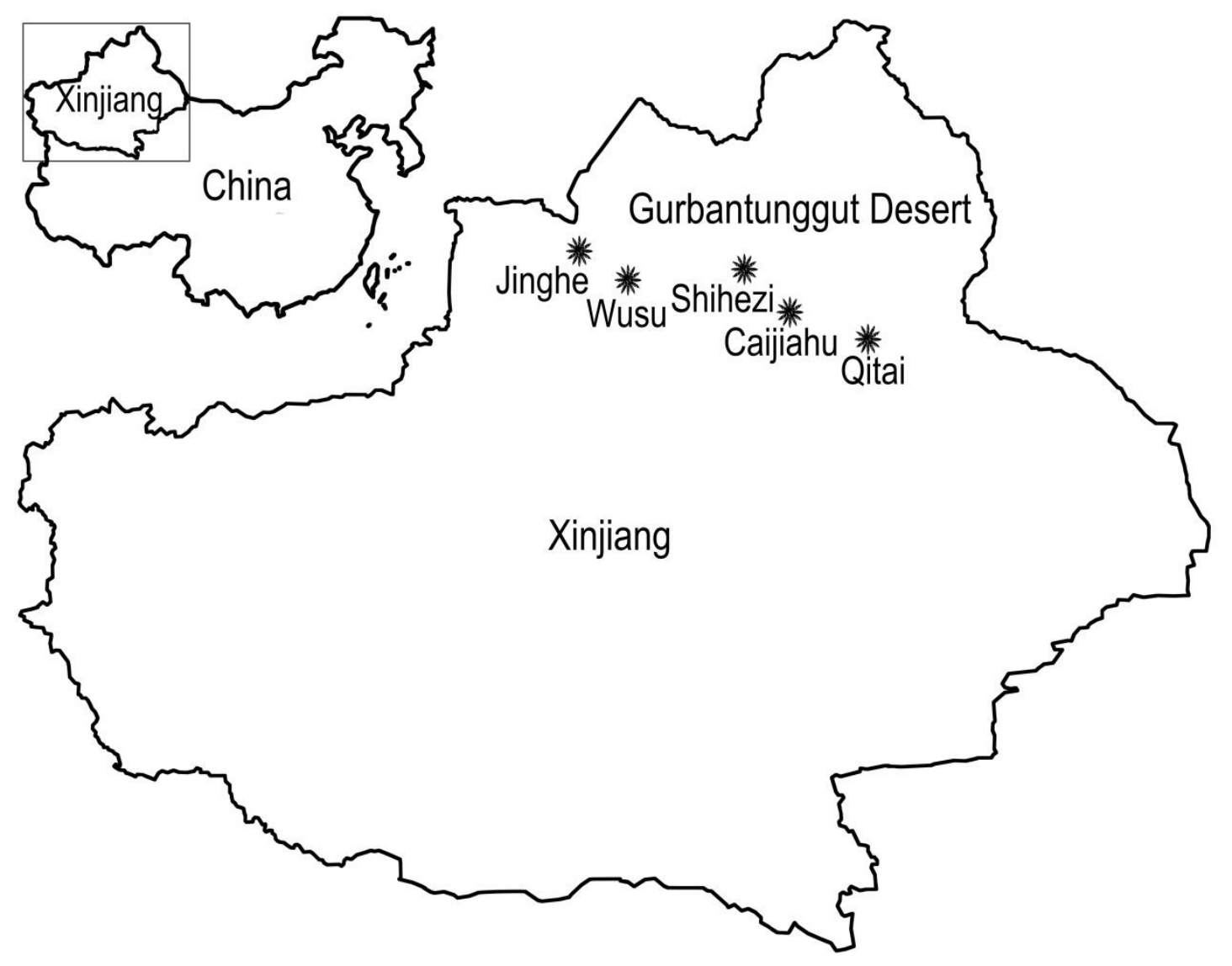

Figure 1. Sample plot in Gurbantunggut Desert of Xinjiang, China

Table 1. The climate conditions and growth characteristics of H. ammodendron in five provenances

\begin{tabular}{|c|c|c|c|c|c|}
\hline Variable & Jinghe & Wusu & Shihezi & Caijiahu & Qitai \\
\hline Average height of tree (m) & $1.23 \pm 0.46 \mathrm{c}$ & $1.22 \pm 0.42 \mathrm{c}$ & $1.70 \pm 0.35 \mathrm{a}$ & $1.77 \pm 0.41 \mathrm{a}$ & $1.44 \pm 0.49 \mathrm{~b}$ \\
\hline Average basal diameter of tree $(\mathrm{cm})$ & $3.99 \pm 0.23 \mathrm{~b}$ & $2.63 \pm 0.15 \mathrm{c}$ & $5.69 \pm 0.18 \mathrm{a}$ & $6.08 \pm 0.23 \mathrm{a}$ & $4.00 \pm 0.21 \mathrm{~b}$ \\
\hline Average crown area of tree $\left(\mathrm{m}^{2}\right)$ & $2.16 \pm 0.19 \mathrm{~b}$ & $1.50 \pm 0.19 \mathrm{~b}$ & $2.94 \pm 0.17 \mathrm{a}$ & $3.22 \pm 0.15 \mathrm{a}$ & $3.14 \pm 0.28 \mathrm{a}$ \\
\hline Longitude (E) & $82^{\circ} 53^{\prime} 35^{\prime \prime}$ & $84^{\circ} 4^{\prime} 56^{\prime \prime}$ & $86^{\circ} 14^{\prime} 44^{\prime \prime}$ & $87^{\circ} 25^{\prime} 1^{\prime \prime}$ & $88^{\circ} 53^{\prime} 20^{\prime \prime}$ \\
\hline Latitude (N) & $44^{\circ} 36^{\prime} 10^{\prime \prime}$ & $44^{\circ} 22^{\prime} 57^{\prime \prime}$ & $45^{\circ} 00^{\prime} 34^{\prime \prime}$ & $44^{\circ} 39^{\prime} 10^{\prime \prime}$ & $44^{\circ} 22^{\prime} 39^{\prime \prime}$ \\
\hline $\begin{array}{l}\text { Maximum velocity from April to June } \\
\left(\mathrm{m} \cdot \mathrm{s}^{-1}\right)\end{array}$ & 5.39 & 5.11 & 5.61 & 6.25 & 6.52 \\
\hline Average annual temperature $\left({ }^{\circ} \mathrm{C}\right)$ & 8.42 & 8.71 & 8.09 & 6.69 & 5.54 \\
\hline Average temperature in July $\left({ }^{\circ} \mathrm{C}\right)$ & 33.31 & 32.86 & 32.73 & 34.03 & 30.46 \\
\hline Average temperature in January $\left({ }^{\circ} \mathrm{C}\right)$ & -19.4 & -18.45 & -20.88 & -24.26 & -24.14 \\
\hline Average annual relative humidity (\%) & 61.84 & 59.41 & 63.55 & 61.61 & 61.87 \\
\hline Average sunlight (h) & 2515.7 & 2547.8 & 2769.4 & 2834.8 & 2837.2 \\
\hline Average annual precipitation (mm) & 111.2 & 180.4 & 225.3 & 153.8 & 205.9 \\
\hline
\end{tabular}

Data are expressed as mean $\pm \mathrm{SE}$, different letters indicate a significant difference among different provenances at $P<0.05$ level. Meteorological data are collected from China Meteorological Data Network (http://data.cma.cn/). 


\section{Measurement of xylem anatomical characteristics}

The bark of all sampled branches were stripped and then the xylem samples were embedded in paraffin without softening or dehydration. The cross sections, radial and tangential sections were prepared using a sliding microtome (MICROM HM430, Germany), with a thickness of $9-11,4.5-5.5$ and $4.5-5.5 \mu \mathrm{m}$, respectively. Sections were dehydrated and stained with safranin and hematoxylin and then the sections were placed on the microscopic slide using synthetic resin. The anatomical features were described according to the recommendations of the IAWA Committee (IAWA Committee, 2004).

To measure the length of the vessels and fibers, xylem samples were treated using Jeffery's method (10\% chromic acid and 10\% nitric acid were mixed according to V:V = 1:1; Wright and Endo, 1993). The isolated samples were placed on the microscopic slide (48 $\mathrm{h}$ after treatment), stained with safranin, and observed under a light microscope.

Photos of sections were taken with a digital camera (Nikon 4500) mounted on a light microscope with $40 \times$ optical magnification (or $10 \times$ optical magnification for the measurement of density of rays $[\mathrm{dR}]$ ). The WinCELL image analysis system (Regent Instruments Inc., Québec, Canada) was used to measure the anatomical variables: height of ray $(\mathrm{hR})$, width of ray $(\mathrm{wR})$, ray cell length $(\mathrm{RCl})$, ray cell width $(\mathrm{RCw})$, wall thickness of ray cell (wtRC), pit diameter of vessel (PdV), diameter of vessel (dV), length of vessel (IV), wall thickness of vessel (wtV), wall thickness of fiber (wtF) and length of fiber $(\mathrm{lF})$. The $\mathrm{dR}$ was calculated by counting the number of rays in an area of $1 \mathrm{~mm}^{2}$. For each variable, 50 random measurements were taken and the mean value per tree was calculated.

\section{Statistical analysis}

All data were analyzed using SPSS 19.0 software. The regression analyses were carried out using Pearson two-tailed tests between the mean value by provenance of the xylem variables and the meteorological factors (from 1991 to 2008), and between each of the xylem variables. The differences in anatomical variables between different provenances were analyzed using a Tukey test for multiple comparisons. The significance of explained variation was analyzed using a generalized linear model (GLM, type III sum of squares; McCullagh and Nelder, 1989), which was set up as follows:

$$
Y=\mu+R+T(R)+\varepsilon
$$

In this model, $Y$ was the response variable, $\mu$ was the general mean, $R$ was the effect of the provenance, $T(R)$ was the effect of the trees (within provenance) and $\varepsilon$ was the error term.

A principal component analysis (PCA) was used to analyze the xylem anatomical variables. The scores of principal components were used to draw the scatter plot, which was used to analyze the combinations of anatomical variables between different plots. 


\section{Results}

\section{Variation in H. ammodendron xylem anatomy}

The GLM showed that provenance significantly affected $(P<0.05)$ the anatomical features of the xylem, apart from in $\mathrm{RCl}, \mathrm{RCw}, \mathrm{PdV}$ and $\mathrm{lF}(P>0.05)$. The tree factor (within provenance) was significant only in $\mathrm{RCl}, \mathrm{RCw}, \mathrm{PdV}$ and $\mathrm{lF}(P<0.05$, Table 2$)$. For most of the anatomical features ( 8 out of a total of 12 ), the provenance significantly explained the total variation. The variation explained was particularly high for the effect of provenance on $\mathrm{dR}$, which was up to 186.07 .

Table 2. The Sources of variation and its significance in anatomical characteristics of $H$. ammodendron xylem

\begin{tabular}{|c|c|c|c|}
\hline \multirow[b]{2}{*}{$\begin{array}{l}\text { Anatomical } \\
\text { characteristic }\end{array}$} & \multirow[b]{2}{*}{ Variable } & \multicolumn{2}{|c|}{ Source } \\
\hline & & Provenance & $\begin{array}{l}\text { Tree } \\
\text { (Within-provenance) }\end{array}$ \\
\hline \multirow[t]{6}{*}{ Rays } & Density of rays $\left(\mathrm{n} / \mathrm{mm}^{2}\right)$ & $186.07 * * *$ & $1.12 \mathrm{~ns}$ \\
\hline & Height of rays $(\mu \mathrm{m})$ & $83.93 * * *$ & $0.08 \mathrm{~ns}$ \\
\hline & Width of rays $(\mu \mathrm{m})$ & $19.53 * *$ & $0.82 \mathrm{~ns}$ \\
\hline & Ray cell length $(\mu \mathrm{m})$ & $2.73 \mathrm{~ns}$ & $9.99 * * *$ \\
\hline & Ray cell width $(\mu \mathrm{m})$ & $1.01 \mathrm{~ns}$ & $27.24 * * *$ \\
\hline & Wall thickness of ray cell $(\mu \mathrm{m})$ & $17.96 * *$ & $0.22 \mathrm{~ns}$ \\
\hline \multirow[t]{4}{*}{ Vessels } & Diameter of vessels $(\mu \mathrm{m})$ & $26.85 * * *$ & $0.43 \mathrm{~ns}$ \\
\hline & Wall thickness of vessels $(\mu \mathrm{m})$ & $5.33 *$ & $0.59 \mathrm{~ns}$ \\
\hline & Pit diameter of vessels $(\mu \mathrm{m})$ & $3.30 \mathrm{~ns}$ & $10.17 * * *$ \\
\hline & Length of vessels $(\mu \mathrm{m})$ & $85.46 * * *$ & $0.38 \mathrm{~ns}$ \\
\hline \multirow[t]{2}{*}{ Fibers } & Wall thickness of fibers $(\mu \mathrm{m})$ & $9.10^{*}$ & $1.99 \mathrm{~ns}$ \\
\hline & Length of fibers $(\mu \mathrm{m})$ & $2.33 \mathrm{~ns}$ & $11.23 * * *$ \\
\hline
\end{tabular}

Asterisks indicate significant sources at $P<0.05(*), P<0.01(* *)$ and $P<0.001(* * *)$; ns not significant.

\section{H. ammodendron xylem anatomy in the five provenances}

There were significant differences $(P<0.05)$ between the xylem anatomical characteristics of $H$. ammodendron in different provenances. Some anatomical parameters significantly changed with the different climate of each provenance. For instance, the average annual precipitation was highest in Shihezi and lowest in Jinghe (Table 1) and significant differences in $\mathrm{dR}, \mathrm{hR}, \mathrm{wR}, \mathrm{RCl}$, wtRC and $\mathrm{dV}$ were found between Jinghe and Shihezi $(P<0.05$; Table 3). The average annual precipitation in Wusu, Caijiahu and Qitai was between Shihezi and Jinghe, and the dR, hR, wtRC and $\mathrm{dV}$ of Wusu, Caijiahu and Qitai were similar (Tables 1 and 3). The highest values of $\mathrm{dR}$, $\mathrm{hR}$, wR, RCw, dV, IV, wtV and $\mathrm{lF}$ were found in Jinghe, the highest value of PdV was found in Wusu, the highest values of $\mathrm{RCl}$ and $\mathrm{wtRC}$ were found in Shihezi and the highest value of wtF was found in Caijiahu. 
Table 3. Anatomical characteristics of H. ammodendron xylem in differenc provenances

\begin{tabular}{|c|c|c|c|c|c|c|}
\hline $\begin{array}{l}\text { Anatomical } \\
\text { characteristic }\end{array}$ & Variable & Jinghe & Wusu & Shihezi & Caijiahu & Qitai \\
\hline \multirow[t]{6}{*}{ Rays } & Density of rays $\left(\mathrm{n} / \mathrm{mm}^{2}\right)$ & $7.71 \pm 1.80 \mathrm{a}$ & $2.41 \pm 0.74 \mathrm{c}$ & $1.46 \pm 0.77 \mathrm{~d}$ & $3.57 \pm 1.10 \mathrm{~b}$ & $3.43 \pm 1.11 \mathrm{~b}$ \\
\hline & Height of rays $(\mu \mathrm{m})$ & $223.74 \pm 88.11 \mathrm{a}$ & $202.70 \pm 73.38 \mathrm{ab}$ & $170.62 \pm 78.80 \mathrm{c}$ & $197.48 \pm 57.93 \mathrm{abc}$ & $194.50 \pm 68.25 b c$ \\
\hline & Width of rays $(\mu \mathrm{m})$ & $29.40 \pm 12.01 \mathrm{a}$ & $22.34 \pm 8.49 \mathrm{bc}$ & $20.80 \pm 11.52 b c$ & $20.17 \pm 6.01 \mathrm{c}$ & $23.97 \pm 6.42 \mathrm{~b}$ \\
\hline & Ray cell length $(\mu \mathrm{m})$ & $19.98 \pm 3.68 \mathrm{~b}$ & $24.08 \pm 5.45 \mathrm{a}$ & $24.98 \pm 5.99 \mathrm{a}$ & $23.74 \pm 5.70 \mathrm{a}$ & $18.67 \pm 5.10 \mathrm{~b}$ \\
\hline & Ray cell width $(\mu \mathrm{m})$ & $11.86 \pm 2.26 \mathrm{a}$ & $10.04 \pm 2.06 \mathrm{~b}$ & $10.57 \pm 1.73 \mathrm{~b}$ & $9.25 \pm 2.05 \mathrm{c}$ & $9.91 \pm 1.30 \mathrm{bc}$ \\
\hline & Wall thickness of ray cell $(\mu \mathrm{m})$ & $2.85 \pm 0.42 \mathrm{~b}$ & $3.02 \pm 0.66 \mathrm{ab}$ & $3.08 \pm 0.44 \mathrm{a}$ & $2.89 \pm 0.49 \mathrm{ab}$ & $2.97 \pm 0.47 \mathrm{ab}$ \\
\hline \multirow[t]{4}{*}{ Vessels } & Diameter of vessels $(\mu \mathrm{m})$ & $60.88 \pm 11.64 \mathrm{a}$ & $57.47 \pm 13.18 \mathrm{ab}$ & $49.06 \pm 14.74 \mathrm{c}$ & $58.60 \pm 15.84 \mathrm{ab}$ & $55.50 \pm 11.92 \mathrm{~b}$ \\
\hline & Wall thickness of vessels $(\mu \mathrm{m})$ & $5.53 \pm 1.18 \mathrm{a}$ & $5.37 \pm 1.18 \mathrm{ab}$ & $5.15 \pm 0.79 b$ & $5.32 \pm 1.28 \mathrm{ab}$ & $5.28 \pm 0.98 \mathrm{ab}$ \\
\hline & Pit diameter of vessels $(\mu \mathrm{m})$ & $3.28 \pm 0.72 b$ & $3.50 \pm 0.71 \mathrm{a}$ & $3.06 \pm 0.64 \mathrm{c}$ & $2.89 \pm 0.48 \mathrm{c}$ & $3.45 \pm 0.77 \mathrm{ab}$ \\
\hline & Length of vessels $(\mu \mathrm{m})$ & $78.03 \pm 14.56 \mathrm{a}$ & $60.57 \pm 10.05 \mathrm{c}$ & $71.25 \pm 11.92 b$ & $64.70 \pm 10.57 \mathrm{c}$ & $71.41 \pm 10.66 b$ \\
\hline \multirow[t]{2}{*}{ Fibers } & Wall thickness of fibers $(\mu \mathrm{m})$ & $2.79 \pm 0.41 \mathrm{~b}$ & $2.64 \pm 0.40 \mathrm{c}$ & $2.72 \pm 0.38 \mathrm{bc}$ & $2.97 \pm 0.43 \mathrm{a}$ & $2.94 \pm 0.41 \mathrm{a}$ \\
\hline & Length of fibers $(\mu \mathrm{m})$ & $263.48 \pm 3.89 \mathrm{a}$ & $234.51 \pm 4.02 b c$ & $276.24 \pm 4.31 \mathrm{a}$ & $247.85 \pm 3.71 \mathrm{~b}$ & $228.41 \pm 3.70 \mathrm{c}$ \\
\hline
\end{tabular}

Data are expressed as mean $\pm \mathrm{SD}$, different letters indicate a significant difference among different provenances at $P<0.05$ level.

\section{Principal component analysis of anatomical features}

The PCA results showed the classification of climatic characteristics in the five provenances (Fig. 2A), and certain anatomical features of $H$. ammodendron were well distinguished by provenance, according to climatic characteristics (Fig. 2B). The dR, $\mathrm{hR}, \mathrm{wR}, \mathrm{dV}$ and $\mathrm{wtV}$ were in accordance with positive scores of $\mathrm{PC} 1$ and characterized the climatic features of Jinghe. The $\mathrm{RCl}$ and wtRC were in agreement with the negative scores of PC1 and characterized the climatic features of Shihezi. The PdV was in accordance with positive scores of PC3 and characterized the climatic features of Wusu. The wtF was in agreement with the negative scores of PC3 and characterized the climatic features of Caijiahu.

\section{Relationships between xylem anatomical characteristics and climatic factors}

The regression analyses between the xylem anatomical variables showed the following significant relationships $(P<0.05$; Table 4$)$ : $\mathrm{dR}$ was positively related to $\mathrm{wR}(\mathrm{r}=0.89)$, $\mathrm{dR}$ was positively related to $\mathrm{wtV}(\mathrm{r}=0.88)$, $\mathrm{hR}$ was positively related to $\mathrm{dV}(\mathrm{r}=0.95), \mathrm{hR}$ was positively related to $\mathrm{wtV}(\mathrm{r}=0.99)$ and $\mathrm{dV}$ was positively related to $\mathrm{wtV}(\mathrm{r}=0.92)$.

The regression analysis between the climatic characteristics and anatomical variables showed the following significant relationships $(P<0.05$; Table 5): average annual precipitation was negatively correlated with $\mathrm{dR}(\mathrm{r}=-0.89$, Eq. 1$), \mathrm{hR}(\mathrm{r}=-0.91, \mathrm{Eq} .2)$, wtV $(\mathrm{r}$ $=-0.93$, Eq. 5) and dV ( $\mathrm{r}=-0.90$, Eq. 4), and positively correlated with wtRC $(r=0.91$, Eq. 3). Maximum wind velocity from April to June was positively related to $\mathrm{wtF}(\mathrm{r}=0.92$, Eq. 6), and average temperature in January was negatively related to $\mathrm{wtF}(r=-0.93$, Eq. 7$)$. 

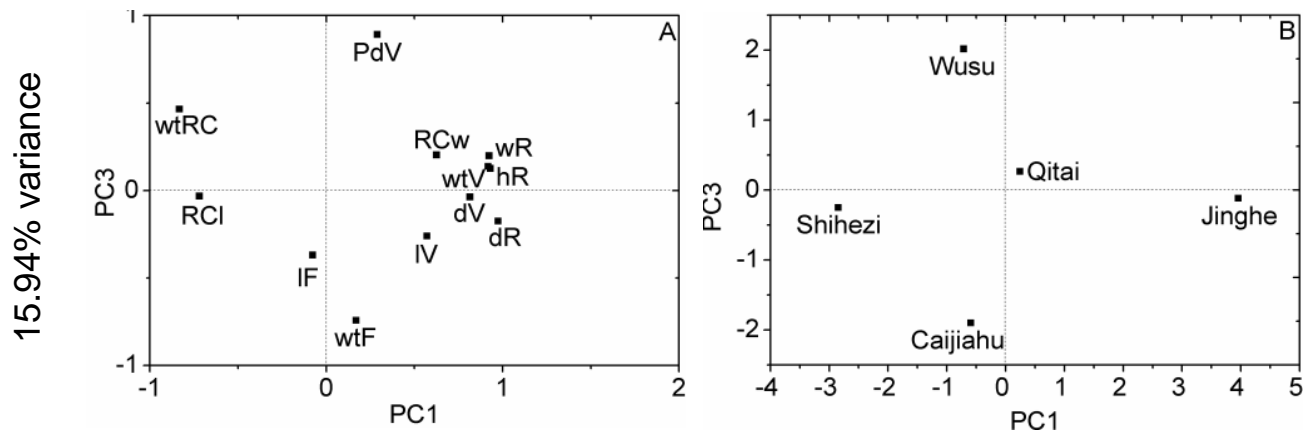

$51.89 \%$ variance

Figure 2. Principal component analysis (PCA) of the anatomical characteristics of H. ammodendron from Gurbantunggut Desert, China

Table 4. Correlation matrix between anatomical variables of $H$. ammodendron xylem

\begin{tabular}{lcccc}
\hline & $\begin{array}{c}\text { Height of } \\
\text { rays }\end{array}$ & $\begin{array}{c}\text { Width of } \\
\text { rays }\end{array}$ & $\begin{array}{c}\text { Diameter of } \\
\text { vessels }\end{array}$ & $\begin{array}{c}\text { Wall thickness of } \\
\text { vessels }\end{array}$ \\
\hline $\begin{array}{l}\text { Density of rays } \\
\text { Height of rays }\end{array}$ & 0.88 & $\underline{0.89}$ & 0.77 & $\underline{0.88}$ \\
$\begin{array}{l}\text { Width of rays } \\
\begin{array}{l}\text { Diameter of } \\
\text { vessels }\end{array}\end{array}$ & & 0.78 & $\underline{0.95}$ & $\underline{0.99}$ \\
\hline
\end{tabular}

Significant correlations shown in underlined $(P<0.05)$. Anatomical variables not included in the table were not significantly related other variables.

Table 5. Correlation matrix between meteorological factors and anatomical variables of $H$. ammodendron xylem

\begin{tabular}{ccccc}
\hline Variables & Linear equation & $\mathrm{r}$ & $P$ & No. \\
\hline $\begin{array}{c}\text { Average annual precipitation (x) and } \\
\text { density of rays (y) }\end{array}$ & $\mathrm{y}=-0.047 \mathrm{x}+12.03$ & -0.89 & 0.04 & (1) \\
$\begin{array}{c}\text { Average annual precipitation (x) and } \\
\text { height of rays (y) }\end{array}$ & $\mathrm{y}=-0.384 \mathrm{x}+265.2$ & -0.91 & 0.03 & $(2)$ \\
$\begin{array}{c}\text { Average annual precipitation (x) and } \\
\text { wall thickness of ray cell (y) }\end{array}$ & $\mathrm{y}=0.001 \mathrm{x}+2.619$ & 0.91 & 0.04 & (3) \\
$\begin{array}{c}\text { Average annual precipitation (x) and } \\
\text { diameter of vessels (y) }\end{array}$ & $\mathrm{y}=-0.09 \mathrm{x}+72.08$ & -0.9 & 0.04 & (4) \\
$\begin{array}{c}\text { Average annual precipitation (x) and } \\
\text { wall thickness of vessels (y) }\end{array}$ & $\mathrm{y}=-0.002 \mathrm{x}+5.832$ & -0.93 & 0.02 & (5) \\
$\begin{array}{c}\text { Maximum velocity from April to June } \\
\text { (x) and wall thickness of fibers (y) } \\
\text { Average temperature in January (x) } \\
\text { and wall thickness of fibers (y) }\end{array}$ & $\mathrm{y}=0.220 \mathrm{x}+1.537$ & 0.92 & 0.03 & (6) \\
\hline
\end{tabular}




\section{Discussion}

This paper studied the branch xylem anatomy of $H$. ammodendron from five provenances in the Gurbantunggut Desert. For most anatomical characteristics, more variation was explained by provenance than by tree (within-provenance variation), which showed that the anatomical characteristics of $H$. ammodendron xylems were notably affected by provenance (Table 3 ).

The variation in $\mathrm{dR}, \mathrm{hR}$ and $\mathrm{wR}$ among different provenances was significant; the variation in $\mathrm{dR}$ was higher than other anatomical characteristics (Table 2). Generally, ray tissues are related to the storage and transport of water and nutrients. The higher ray frequency means that the xylem can accumulate more water and starch, and the starch can provide metabolites to reduce the impact of water stress (Esteban et al., 2012). For example, Acacia tortilis subsp. raddiana (Savi) Brenan increased its ray density to cope with the shortage of water under drought stress (Aref et al., 2013).

In this study, the average annual precipitation in Jinghe was the lowest of the studied provenances, but the values of $\mathrm{dR}, \mathrm{hR}$ and $\mathrm{wR}$ were the highest (Table 3). This may be because drought stress favored the production of ethylene in the plants (Chen et al., 2002) and ethylene promoted anticlinal division in fusiform initials, increasing the density and/or size of rays (Pramod et al., 2013). The $\mathrm{dR}$ and $\mathrm{hR}$ were negatively related to average annual precipitation ( $P<0.05$; Table 5, Eq. 1 and Eq. 2$)$, which shows that the xylem rays of $H$. ammodendron favor efficiency over safety, meaning that rays were tall and wide to reduce water shortages under water stress (Leal et al., 2006).

The increase in ray size often leads to a decrease in the mechanical strength of the xylem (Carlquist et al., 1984; Rahman et al., 2005). However, we did not find an increase in wtRC in $H$. ammodendron in response to drought stress. Of the five provenances, the maximum wtRC was found in Shihezi, which has the highest average annual precipitation, rather than in Jinghe, which has the lowest average annual precipitation (Table 3). The regression analysis showed that wtRC was positively related to the average annual precipitation $(P<0.05$; Table 5, Eq. 3). Therefore, it was difficult to explain the variations in wtRC according to changes in precipitation. The ray cell may have thick or thin walls (Carlquist, 2001; Rajput et al., 2013), but only a few species have thick-walled rays. For example, rays in Symbolanthus macranthus G. Don are thick-walled, with a thickness of $2.5 \mu \mathrm{m}$ (Carlquist and Grant, 2005). Although the wall thickness of rays in $H$. ammodendron did not increase with decreasing precipitation, the walls of rays in all five provenances were generally thickened, with a mean thickness of $2.96 \mu \mathrm{m}$. This implies that the rays of $H$. ammodendron have thick walls to increase the safety of storage and radial transport of water. The decrease in mechanical strength caused by the increase in ray size and density could be improved by other aspects of growth. For example, the tree height, basal diameter and crown area in Jinghe was lower than in Shihezi $(P<0.05$; Table 1), which could decrease the trees' requirement for mechanical strength (Alves and Angyalossy-Alfonso, 2002).

The precipitation in Jinghe was low, but the values of $\mathrm{dV}$ and $\mathrm{IV}$ in $H$. 
ammodendron were higher in Jinghe than in other provenances, which indicated that the efficiency of water transport was the priority in xylem anatomy (Table 3; Zanne et al., 2010). Plants growing in drought stress often have narrow vessels to increase cavitation resistance and hydraulic safety (Cai and Tyree, 2010). However, in our experiment the $\mathrm{dV}$ was negatively related to the average annual precipitation $(P<0.05$; Table 5, Eq. 4). Vessels with large diameters were susceptible to embolization due to drought stress (Al-Khalifah et al., 2006). In H. ammodendron, there was an increase in the diameter of vessels to improve transport under sparse precipitation, which likely compensates for the reduction in transport induced by cavitation (Galle et al., 2010). Our results are in accordance with the studies on xylem hydraulic properties in Fagus sylvatica L. and Salix psammophila C. Wang et Ch. Y. Yang (Hajek et al., 2016; Li et al., 2016). However, this did not mean that transport safety was not considered in the structure of the vessels. The $\mathrm{wtV}$ may be related to drought adaptation because the vessel wall is thicker when arid-adapted plants experience greater negative xylem pressures (Kohonen and Helland, 2009), which could decrease the sensitivity to embolism (Hacke et al., 2001).

Our study indicated that precipitation in Jinghe was low, but the $\mathrm{wtV}$ in this region of $5.53 \pm 0.67 \mu \mathrm{m}$ was the highest of all the provenances (Table 3). The wtV was negatively related to the average annual precipitation $(P<0.05$; Table 5 , Eq. 5$)$ and was positively related to the $\mathrm{dV}(P<0.05$; Table 4$)$. These correlations indicate that in the more arid Jinghe, the $H$. ammodendron had wide vessels to improve conductivity and increased $\mathrm{wtV}$ to guarantee transport safety. Similar results were reported for Acacia ehrenbergiana Hayne (Aref et al., 2013). The positive correlation between wtV and $\mathrm{dV}$ indicated no trade-off between efficiency and safety, which is in agreement with many studies (Maherali et al., 2006; Plavcová and Hacke, 2012; Hajek et al., 2016). The trade-off between efficiency and safety is based on pit-level traits (Sperry et al., 2006; Christman et al., 2012), so if the plasticity of $\mathrm{dV}$ and $\mathrm{wtV}$ in $H$. ammodendron is high enough, we might not find the trade-off between efficiency and safety during the development of the xylem.

Fibers provide mechanical strength to steady stems and vessel conduction against implosion due to negative pressure (Sperry, 2003; Jacobsen et al., 2005). In the Gurbantunggut Desert, the maximum wind velocity of the year occurred from April to June. This maximum was positively related to the $\mathrm{wtF}$, indicating that the $\mathrm{wtF}$ is adapted to variation in wind velocity in the Gurbantunggut Desert. In other words, a thicker fiber cell wall could provide higher mechanical resistance and protect the transport safety of vessels in strong wind conditions (Alves and Angyalossy-Alfonso, 2002).

The stress of freeze-thaw can result in embolism and cavitation in plants (Sevanto et al., 2012). Many studies have reported that smaller vessels are less sensitive to this embolism and cavitation (Davis et al., 1999; Feild et al., 2002). The average temperature in January in Caijiahu was the lowest of all the study sites, but the $\mathrm{dV}$ of $H$. ammodendron was not the smallest in this provenance (Table 3), showing that the xylem of the plant did not decrease the $\mathrm{dV}$ in response to the stress of freeze-thaw. The area of fiber cell wall is positively related to cavitation resistance (Jacobsen et al., 
2005), indicating that a thicker wtF would mean higher cavitation resistance. The average temperature in January was negatively related to the $\mathrm{wtF}(P<0.05$; Table 5, Eq. 7), implying that $\mathrm{wtF}$ increased in order to enhance resistance to cavitation under cold stress (Jacobsen et al., 2005).

The results of PCA indicated that the PC1 of Jinghe, with a maximum positive score, characterized the lowest precipitation and was in accordance with the highest values of $\mathrm{dR}, \mathrm{hR}, \mathrm{wR}, \mathrm{dV}$ and wtV. This indicates that the high water storage and transport by the xylem was a response to the sparse precipitation, as also illustrated by the negative correlations between average annual precipitation and $\mathrm{dR}, \mathrm{hR}, \mathrm{dV}$ and $\mathrm{wtV}$ (Table 5). The PC3 of Wusu, with a maximum positive score, characterized the lowest value of maximum wind velocity from April to June, which was in accordance with the lowest values of wtF, indicating low mechanical properties. The $\mathrm{wtF}$ in Caijiahu was the highest among the five provenances, indicating that the higher the value of maximum wind speed, the thicker the $\mathrm{wtF}$ in xylems, as also evidenced by the positive correlation between wtF and maximum wind velocity from April to June (Table 5, Eq. 6).

The present study showed how anatomical features of xylems in H. ammodendron responded to climatic factors. The xylem responded to more arid conditions by increasing the $\mathrm{dR}$ and $\mathrm{hR}$ to improve water and starch storage. The xylem increased in both $\mathrm{dV}$ and wtV to account for both efficiency and safety in the xylem, which did not support the suggestion of a trade-off between efficiency and safety (Plavcová and Hacke, 2012; Hajek et al., 2016). The plants responded to the low temperature in January and strong winds from April to June by increasing wtF. These results indicate that there is high plasticity of xylem characteristics in H. ammodendron in response to different desert environmental conditions, explaining the adaptation of this plant to a wide geographical range across Asian and African deserts.

Acknowledgements. This study was funded by the National Natural Science Foundation of China (grant number 31500471).

\section{REFERENCES}

[1] Al-Khalifah, N.S., Khan, P.R., Al-Abdulkader, A.M., Nasroun, T. (2006): Impact of water stress on the sapwood anatomy and functional morphology of Calligonum comosum. -IAWA J. 27: 299-312.

[2] Alves, E., Angyalossy-Alfonso, V. (2002): Ecological trends in the wood anatomy ofsome Brazilian species. 2. Axial parenchyma, rays and fibres. -IAWA J. 23:391-418.

[3] Aref, M.I., Ahmed, A.I., Khan, P.R., Ei-Atta, H.A., Iqbal, M. (2013): Drought-induced adaptive changes in the seedling anatomy of Acacia ehrenbergiana and Acacia tortilis subsp. raddiana. -Trees 27: 959-971.

[4] Bedunah, D.J., Schmidt, S.M. (2000): Rangelands of Gobi Gurvan Saikhan National Conservation Park, Mongolia. -Rangelands Archives 22: 18-24.

[5] Cai, J., Tyree, M.T. (2010): The impact of vessel size on vulnerability curves: data and models for within-species variability in saplings of aspen, Populus tremuloides Michx. -Plant Cell Environ. 33:1059-1069. 
[6] Carlquist, S.J. (2001): Comparative wood anatomy: systematic, ecological, and evolutionary aspects of dicotyledon wood, 2nd edn. -Springer, Berlin.

[7] Carlquist, S., Eckhart, V.M., Michener, D.C. (1984): Wood anatomy of Polemoniaceae. -Aliso 10: 547-572.

[8] Carlquist, S., Grant, J.R. (2005): Wood anatomy of Gentianaceae, tribe Helieae, in relation to ecology, habit, systematics, and sample diameter. -Brittonia 57: 276-291.

[9] Chen, S.L., Wang, S.S., Hüttermann, A., Altman, A. (2002): Xylem abscisic acid accelerates leaf abscission by modulating polyamine and ethylene synthesis in water-stressed intact poplar. -Trees 16: 16-22.

[10] Christensen-Dalsgaard, K.K., Ennos, A.R. (2012): Effects of drought acclimation on the mechanical properties of Ochroma pyramidale, Betula pendula and Acacia karroo tree seedling stems. -Forestry 85: 215-223.

[11] Christman, M.A., Sperry, J.S., Smith, D.D. (2012): Rare pits, large vessels and extreme vulnerability to cavitation in a ring-porous tree species. -New Phytol. 193: 713-720.

[12] Davis, S.D., Sperry, J.S., Hacke, U.G. (1999): The relationship between xylem conduit diameter and cavitation caused by freeze-thaw events. -Am. J. Bot. 86: 1367-1372.

[13] Esteban, L.G., Martín, J.A., de Palacios, P., García-Fernández, F., López, R. (2010): Adaptive anatomy of Pinus halepensis trees from different Mediterranean environments in Spain. -Trees Struct. Funct. 24: 19-30.

[14] Esteban, L.G., Martín, J.A., de Palacios, P., García-Fernández, F. (2012): Influence of region of provenance and climate factors on wood anatomical traits of Pinus nigra Arn. subsp. salzmannii. -Eur. J. Forest Res. 131: 633-645.

[15] Fahn, A., Cutler, D.F. (1992): Xerophytes. Handbuch der Pflanzenanatomie, Spezieller Teil, Band XIII, Teil 3. -Gebrüder Borntraeger, Berlin.

[16] Feild, T.S., Brodribb, T., Holbrook, N.M. (2002): Hardly a relict: freezing and the evolution of vesselless wood in Winteraceae. -Evolution 56: 464-478.

[17] Galle, A., Esper, J., Feller, U., Ribas-Carbo, M., Fonti, P. (2010): Responses of wood anatomy and carbon isotope composition of Quercus pubescens saplings subjected to two consecutive years of summer drought. -Ann. For. Sci. 67: 809-809.

[18] Hacke, U.G., Sperry, J.S., Pockman, W.T., Davis, S.D., McCulloh, K.A. (2001): Trends in wood density and structure are linked to prevention of xylem implosion by negative pressure. -Oecologia 126: 457-461.

[19] Hajek, P., Kurjak, D., von Wühlisch, G., Delzon, S., Schuldt, B. (2016): Intraspecific variation in wood anatomical, hydraulic, and foliar traits in ten European beech provenances differing in growth yield. -Front. Plant Sci. 7: 791.

[20] Heklau, H., Gasson, P., Schweingruber, F., Baas, P. (2012): Wood anatomy of Chenopodiaceae (Amaranthaceae s.1. ). -IAWA J. 33: 205-232.

[21] Huang, Z.Y., Zhang, X.S., Zheng, G.H., Gutterman, Y. (2003): Influence of light, temperature, salinity and storage on seed germination of Haloxylon ammodendron. -J. Arid Environ. 55: 453-464.

[22] Huang, P.Y., Xiang, B., Li, Q.J., Xu, Z.H. (2009): Relationship between Haloxylon ammodendron seedling dynamics and habitat before summer. -J. Desert Res. 29: 87-94 (in Chinese).

[23] IAWA Committee. (2004): IAWA list of microscopic features for softwood identification. -IAWA J. 25: 1-70.

[24] Jacobsen, A.L., Ewers, F.W., Pratt, R.B., Paddock, W.A., Davis, S.D. (2005): Do xylem fibers affect vessel cavitation resistance? -Plant Physiol. 139: 546-556.

[25] Kohonen, M.M., Helland, A. (2009): On the function of wall sculpturing in xylem conduits. -J. Bionic. Engin. 6: 324-329.

[26] Leal, S., Sousa, V.B., Pereira, H. (2006): Within and between-tree variation in the biometry of wood rays and fibres in cork oak (Quercus suber_L.). -Wood Sci. 
Technol. 40: 585-597.

[27] Li, J.F., Wada, H., Matsuzaki, H. (2015): Radial growth rate through successive cambia in Haloxylon ammodendron (Chenopodiaceae) from the Gurbantünggüt Desert, Northwestern China, determined by a series of radiocarbon dating. -Geochem. J. 49: $39-51$.

[28] Li, Y.Y., Chen, W.Y., Chen, J.C., Shi, H. (2016): Contrasting hydraulic strategies in Salix psammophila and Caragana korshinskii in the southern Mu Us Desert, China.-Ecol. Res. 31: 869-880.

[29] Lv, C.Y., Zhang, X.M., Liu, G.J., Deng, C.Z. (2012): Seed yield model of Haloxylon ammodendron (C.A.Meyer) bunge in Junggar basin, China. -Pak. J. Bot. 44: 1233-1239.

[30] Lv, C.Y., Zhang, X.M., Liu, G.J. (2015): Variability of Haloxylon ammodendron (C.A.Mey) bunge populations from different habitats. -Pak. J. Bot. 47: 2135-2141.

[31] Maherali, H., Moura, C.F., Caldeira, M.C., Willson, C.J., Jackson, R.B. (2006): Functional coordination between leaf gas exchange and vulnerability to xylem cavitation in temperate forest trees. -Plant, Cell Environ. 29: 571-583.

[32] Margaris, N.S, Papadogianni, P. (1977): The ratio of ray and fusiform initials in some plants dominating Mediterranean formations in Greece. -Flora 166: 219-222.

[33] Martin, J.A., Esteban, L.G., de Palacios, P., Fernandez, F.G. (2010): Variation in wood anatomical traits of Pinus sylvestris L. between Spanish regions of provenance. -Trees Struct. Funct. 24: 1017-1028.

[34] McCullagh, P., Nelder, J.A. (1989): Generalized linear models, 2nd edn. -Chapman and Hall, London.

[35] Menezes-Silva, P.E., Cavatte, P.C., Martins, S.C.V., Reis, J.V., Pereira, L.F., Avila, R.T., Almeida, A.L., Ventrella, M.C., DaMatta, F.M. (2015): Wood density, but not leaf hydraulic architecture, is associated with drought tolerance in clones of Coffea canephora. -Trees 29: 1687-1697.

[36] Plavcová, L., Hacke, U.G. (2012): Phenotypic and developmental plasticity of xylem in hybrid poplar saplings subjected to experimental drought, nitrogen fertilization, and shading. -J. Exp. Bot. 63: 6481-6491.

[37] Pramod, S., Patel, P.B., Rao, K.S. (2013): Influence of exogenous ethylene on cambial activity, xylogenesis and ray initiation in young shoots of Leucaena leucocephala (Lam.) de Wit. -Flora 208: 549-555.

[38] Pyankov, V.I., Black Jr, C.C., Artyusheva, E.G., Voznesenskaya, E. V., Kuu, M.S.B., Edwards, G.E. (1999): Features of photosynthesis in Haloxylon species of Chenopodiaceae that are dominant plants in Central Asia desert. - Plant Cell Physiol. 40: $125-134$.

[39] Rahman, M., Fujiwara, S., Kanagawa, Y. (2005): Variations in volume and dimensions of rays and their effect on wood properties of teak. - Wood Fiber Sci. 37: 497-504.

[40] Rajput, K.S., Patil, V.S., Rao, K.S. (2013): Wood anatomy and the development of interxylary phloem of Ipomoea hederifolia Linn. (Convolvulaceae). - J. Plant Growth Regul. 32: 654-662.

[41] Sevanto, S., Holbrook, N.M., Ball, M.C. (2012): Freeze/thaw-induced embolism: probability of critical bubble formation depends on speed of ice formation. - Front Plant Sci. 3: 107.

[42] Sheng, Y., Zheng, W., Pei, K., Ma, K. (2005): Genetic variation within and among populations of a dominant desert tree Haloxylon ammodendron (Amaranthaceae) in China. -Ann. Bot. 96: 245-252.

[43] Song, Y.Y., Zhou, C.B. (2015): Multiple bands characteristics of tree-ring and age of Haloxylon ammodendron in Gurbantunggut Desert. - Pak. J. Bot. 47: 615-622.

[44] Sperry, J.S. (2003): Evolution of water transport and xylem structure. - Int. J. Plant Sci. 164: S115-S127. 
[45] Sperry, J.S., Hacke, U.G., Pittermann, J. (2006): Size and function in conifer tracheids and angiosperm vessels. - Am. J. Bot. 93: 1490-1500.

[46] Tobe, K., Li, X.M., Omasa, K. (2000): Effects of sodium chloride on seed germination and growth of two Chinese desert shrubs, Haloxylon ammodendron and $H$. persicum (Chenopodiaceae). - Aust. J. Bot. 48: 455-460.

[47] von Wehrden, H., Wesche, K., Miehe, G. (2009): Plant communities of the southern Mongolian Gobi. - Phytocoenologia 39: 331-376.

[48] Wright, J.A., Endo, M. (1993): Wood density of four-year-old clones of Eucalyptus grandisfrom sixteen traits in Colombia. - Wood Fiber Sci. 25: 333-338.

[49] Yang, S.M., Furukawa, I. (2003): Anatomical features of a rayless woody xerophyte Haloxylon ammodendron. - Sand Dune Res. 49: 99-104.

[50] Zanne, A. E., Westoby, M., Falster, D.S., Ackerly, D.D., Loarie, S.R., Arnold, S.E., Coomes, D.A. (2010): Angiosperm wood structure: global patterns in vessel anatomy and their relation to wood density and potential conductivity. - Am. J. Bot. 97: 207-215.

[51] Zas, R., Moreira, X., Ramos, M., Lima, M.R.M., da Silva, M.N., Solla, A., Vasconcelos, M. W., Sampedro, L. (2015): Intraspecific variation of anatomical and chemical defensive traits in Maritime pine (Pinus pinaster) as factors in susceptibility to the pinewood nematode (Bursaphelenchus xylophilus). - Trees 29: 663-673.

[52] Zhou, C.B., Song, Y.Y. (2015): Influence of different longitudinal dune positions in the Gurbantunggut Desert on the reproduction of Haloxylon Ammodendron seedlings. - Appl. Ecol. Env. Res. 13: 99-103. 